\title{
SYNTHESIS AND CHARACTERIZATION FILM POLYPROPYLENE/RICE HUSK AND RICE HUSK ASH NANOCOMPOSITES
}

\author{
S. Aprilia ${ }^{1, *}$, B. Arifin ${ }^{1}$, Nasrul Arahman ${ }^{1}$, Abubakar1, Amri Amin $^{2}$, \\ A.V. Wicaksono ${ }^{1}$ and D. Bakhtiar ${ }^{1}$ \\ ${ }^{1}$ Department of Chemical Engineering, Engineering Faculty, Syiah Kuala University, \\ Darussalam-23111, Banda Aceh, Indonesia \\ ${ }^{2}$ Department of Mechanical Engineering, Abulyatama University, \\ Lampoh Keude, Aceh Besar, Indonesia \\ *E-mail: sriaprilia@unsyiah.ac.id
}

\begin{abstract}
Agriculture wastes such as rice husk and rice husk ash have investigated as filler in film polypropylene composites. These wastes have potentiality as filler in polymer composites as reinforcement. In this study, the development of film polypropylene filled with rice husk and rice husk ask after preparing as nanofiller as the effect of filler loading has been done. Loading rice husk and rice husk ash into polypropylene matrix of $3 \mathrm{wt} \%$, $6 \mathrm{wt} \%$, and $9 \mathrm{wt} \%$ and compared with polypropylene which is not filled. Film polypropylene nanocomposites were analyzed the structure of functional group by FTIR, fracture surface by SEM, water absorption, tensile strength and elongation at break. The presence of silica in film composites has indicated at wavelength $1070 \mathrm{~cm}^{-1}$ in the form of the functional group of Si-O-Si. SEM image has shown that the films are not smooth when silica adding in the film composites, because of the aggregation of silica is not good dispersion in the polypropylene matrix. Water absorption of film polypropylene composites increases when increasing filler loading. The mechanical test has conducted the tensile strength of composites increase by increasing filler loading but elongation at break decrease by increasing filler loading. Polypropylene nanocomposites filled with rice husk ash have good performance than filled with rice husk because of chemical content in the filler loading.
\end{abstract}

Keywords: Rice husk, rice husk ash, nanofiller, polypropylene nanocomposites, characterization, mechanical analysis, and water absorption

(C) RASĀYAN. All rights reserved

\section{INTRODUCTION}

Agricultural solid waste disposal becomes one of the environmental problems at recently. Handling solid waste is not the solution to solve the waste but it will cause new problems. Until now, farmers only burn solid agricultural waste and will pollute the surrounding air. Researchers, now concern on the utilization of agricultural solid waste to increase value-added. One of agricultural solid waste is rice husks that can be utilized as filler in composite polymers. Rice husks contain $40 \%$ cellulose, $30 \%$ lignin, and $20 \%$ ash. The result of burning rice husks will be rice husk ash which has amorphous silica content about 85-90\% and carbon about $10-15 \% .{ }^{1}$ Rice husk is a raw material from biological sources such as silica into a new field that is very well developed in Indonesia with nano technology. ${ }^{2,3}$ Arifin et $\mathrm{al}^{4}$, found that the silica contents of rice husks $82.54 \%$ and the rice husk ask $89.84 \%$. The chemical of silica rice husk and rice husk ash in the form of $\mathrm{SiO}_{2}$. Guptha et al, ${ }^{5}$ mentioned that adding the rice husk ash in the polymer matrix will increase the flexural strength.

Thermoplastics commonly used with lignocellulose material are polypropylene, polyvinylchloride, lowhigh density polyethylene, polyethylene terephthalate, polystyrene. ${ }^{6}$ These thermoplastics must melt or soften at below degradation temperature of the lignocellulosic component, normally $200-220{ }^{\circ} \mathrm{C}^{7}$ Polypropylene is one of the most widely used types of polymers in everyday life, including glass, plastic

Rasayan J. Chem., 12(2), 994-1001(2019)

http://dx.doi.org/10.31788/RJC.2019.1225144

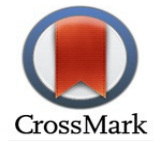


plates, key chains, and in various fields such as industry as a food and beverage packaging. However polypropylene has a very high degree of fragility, it is characterized by a low specific gravity value of about $0.85-0.90 \mathrm{gr} / \mathrm{cm}^{3}{ }^{8}$ It is, therefore, necessary to add a strengthening and filler material which can improve the fragility and increase the properties of stress-cracking and high-temperature resistance. The addition of fillers in polypropylene will make better adhesion so that the strength level increases (stiffness decreases). ${ }^{9}$ Polypropylene nanocomposites attract great interest in industry and academics because they often show remarkable improvements in properties when compared to pure polymers or conventional micro and macro composites. ${ }^{29}$

The problem in the polymer matrix filled with natural filler that can be made composites are good mechanical properties there are filler loading, size of particle and distribution filler in the matrix. To solved this problem many researchers has developed the filler size, loading by many methods. The amount of loading filler in the polymer matrix will be affected in the properties of composites. ${ }^{10}$ The development of nano-based technologies in applications such as composite materials is an alternative to producing new materials, as well as solutions for environmental problems and natural resource constraints. ${ }^{11}$ The addition of composite material as a filler in nano size when made into a composite and spread evenly will improve the quality of relaxation properties and molecular mobility. An increase in the amount of nano-sized filler $(<10 \%)$ can improve biocompatible, biodegradable, and special properties according to the filler characteristics used. ${ }^{12}$ The addition of Bioparticles as fillers into polypropylene polymers into composites can reduce dependence on the use of mineral nanoparticles such as calcium carbonate, mica and others. To replace the use of such nanoparticles can be used renewable raw materials such as rice waste. The addition of the rice husk particles in the polymer by adding the particles into the polymer chains and pores thus causing the arrangement between the particles to be closer so that the interaction between particles becomes increased which affects the strength and stiffness produced. ${ }^{13}$

Marlina et al, ${ }^{13}$ has conducted a study on the effect of silica and rice husk loading on composite material compressive strength with the conclusion that by inserting nanoparticles into polymer pores and chains will lead to reduced polymer chain mobility, so that the arrangement between particles becomes closer and the distance the particles get closer together. Amalia et al. ${ }^{14}$ have also conducted research on the effect of the silica content in polypropylene composites. The polypropylene ingredients used from pure drinking water and silica wastes, with the best tensile strength test results of $77.80 \mathrm{~N} / \mathrm{m}^{2}$ on the silica composition in the propylene composite of 0.10 grams. However, increasing the composition of the silica in the propylene composite is too high or low can decrease the value of tensile strength in polypropylene. In this study two kinds of rice husk and rice husk ash are used as a filler to enhance the properties of polypropylene nanocomposites on the effect of filler loading towards physical, mechanical and morphological properties.

\section{Materials}

\section{EXPERIMENTAL}

The materials used in the manufacture of polypropylene nanocomposites are Polypropylene (PP) density $0.9 \mathrm{~g} / \mathrm{cm}^{3}$, melt flow index $3.5 \mathrm{~g} / 10$ minute, Xylene as a solvent. Aquades, rice husk, and rice husk ash from Aceh Province, Indonesia. The rice husk and rice husk ash prepared followed by Arifin et al, $2018^{4}$. Nanoparticles from rice husk and rice husk ash after removed moisture content were washed and dried in an oven for overnight. The dried sample is reduced in size by using a blender and to obtain a smaller size refining with a ball mill for $12 \mathrm{~h}$. Nanoparticle used after a screen from 325 meshes.

\section{Manufacture of Composite Polymers}

The process of preparing a polypropylene nanocomposites by dissolving a polypropylene using xylene with a temperature of $190^{\circ} \mathrm{C}$ and then filler loading (rice husk and rice husk ash) with various concentrations of $3 \mathrm{wt} \%, 6 \mathrm{wt} \%$, and $9 \mathrm{wt} \%$, while mixing until the bioparticles appear to have spread evenly in the solution. The solution was cast on flat stainless steel at a temperature of $150^{\circ} \mathrm{C}$.

\section{FTIR Analysis}

The structure of functional group polypropylene nanocomposites has analysis by FTIR. The FITR analysis was performed using a Shimadzu Prestige FT-IR 6400 instrument with wavelength 4000 - 400 
$\mathrm{cm}^{-1}$. First, the sample was scraped and dried in the oven for 24 hours at $60{ }^{\circ} \mathrm{C} .5 \mathrm{gr}$ sample mixed with $\mathrm{KBr}$ to get $100 \mathrm{gr}$. Samples were made in pellet form and analyzed at these wavelengths.

\section{SEM Analysis}

To determine the structure formed on polypropylene nanocomposites analyze by SEM. SEM analysis was performed using a Hitachi TM300 tool. The sample is attached to a holder then in a thin layer of platinum (2.5-2.8 $\mathrm{nm}$ thick) in a vacuum state. SEM enlargement is 500X.

\section{Physical and Mechanical Properties \\ Water Absorption Analysis}

Analysis of water absorption in polypropylene nanocomposites was done by immersing the sample size 2 $\mathrm{cm} \times 2 \mathrm{~cm}$ in $50 \mathrm{ml}$ of water for 5 days, and then calculated the volume of water absorbed.

\section{Tensile and Elongation at Break Test}

Tensile strength and flexural strength analyses were performed using the HT-8503 Computer Type Universal Testing Machines device. The polypropylene nanocomposites sample was cut following ASTM D638. The sample is used five repetitions to obtain the average data of tensile strength and elongation at break.

\section{Functional Group of Polypropylene Composites}

\section{RESULTS AND DISCUSSION}

The obtained FTIR spectra for polypropylene nanocomposites filled with rice husk and rice husk ash were performed in Fig.-1 and Fig.-2. From Fig.-1 and 2 are the results of FTIR composite of pure polypropylene with the addition of rice husk filler and rice husk ash. The overall result shows that structures are almost the same with pure polypropylene polymers. However, when viewed in greater detail, there is a difference that is in the rice husk spectrum $1645 \mathrm{~cm}^{-1}$ and the ash of rice husk ash at 1624 $\mathrm{cm}^{-1}$ shows the existence of alkene functional groups $(\mathrm{C}=\mathrm{C})$ and the spectra rice husk at $1076 \mathrm{~cm}^{-1}$ and spectra rice husk ash at $1078 \mathrm{~cm}^{-1}$, it isindicates the presence of a silica functional group in the form of $\mathrm{Si}$ $\mathrm{O}-\mathrm{Si}$. The existence of such bonds may state that the composite contains silica because of the rice husk filler. From the FTIR spectra, it was concluded that the addition of filler in the form of silica from rice husk and rice husk ash interacted with polypropylene polymer by hydrogen bond in spectra $3319 \mathrm{~cm}^{-1}$ and ester bond on $2257 \mathrm{~cm}^{-1}$ spectra thus improving adhesion properties between filler and polypropylene polymer matrix. Turmanova et al., 2012 implies that the structure of polypropylene is very important information when filled with different fillers can be obtained by comparing the filler FTIR spectrum, first and filled with polypropylene. The assignments on the structure of polypropylene nanocomposites compared with Coates, (2000) ${ }^{15}$ was summaries in Table-1.

Table-1: Interpretation of FTIR on Polypropylene Nanocomposites Compared with *Coates, 2000

\begin{tabular}{c|c|c|c}
\hline Wavelength $\left(\mathrm{cm}^{-1}\right)$ & $\begin{array}{c}\text { Literature Wavelength* } \\
\left(\mathrm{cm}^{-1}\right)\end{array}$ & Bonding & Type of Functional Group \\
\hline 3319 and 3308 & $3400-3200$ & $\mathrm{O}-\mathrm{H}$ & no bending \\
\hline 2976 & $3000-2820$ & $\mathrm{C}-\mathrm{H}_{\text {str }}$ & methyl $\left(-\mathrm{CH}_{3}\right)$ \\
\hline 2852 & $3000-2820$ & $\mathrm{C}-\mathrm{H}_{\text {str }}$ & methyl $\left(-\mathrm{CH}_{2}\right)$ \\
\hline 2257 and 2245 & $2300-2000$ & $-\mathrm{COO}-$ & ester \\
\hline 1078 and 1076 & $1095-1075$ & Si-O-Si & silica \\
\hline 1450 & $1470-1430$ & $\mathrm{C}-\mathrm{H}_{\text {bend }}$ & methyl \\
\hline 1377 & $1380-1370$ & $\mathrm{C}-\mathrm{H}_{\text {bend }}$ & - \\
\hline 992 & $995-985$ & $\mathrm{C}-\mathrm{H}$ & aromatic \\
\hline
\end{tabular}

\section{Fracture Surface Structure of Nanocomposites}

Fracture surface structure of polypropylene nanocomposites analyzed by SEM. The result of the structure of polypropylene nanocomposites filled with rice husk and rice husk ash shown in Fig.-3. Figure-3A is a polypropylene without filler, Figure-3B is a polypropylene nanocomposite with rice husk and Figure-3C 
RASĀYAN J. Chem.

Vol. 12 | No. 2 |994 - 1001| April - June | 2019

is a polypropylene nanocomposite filled with rice husk ash. The filler into the matrix polypropylene are $3 \mathrm{wt} \%$.

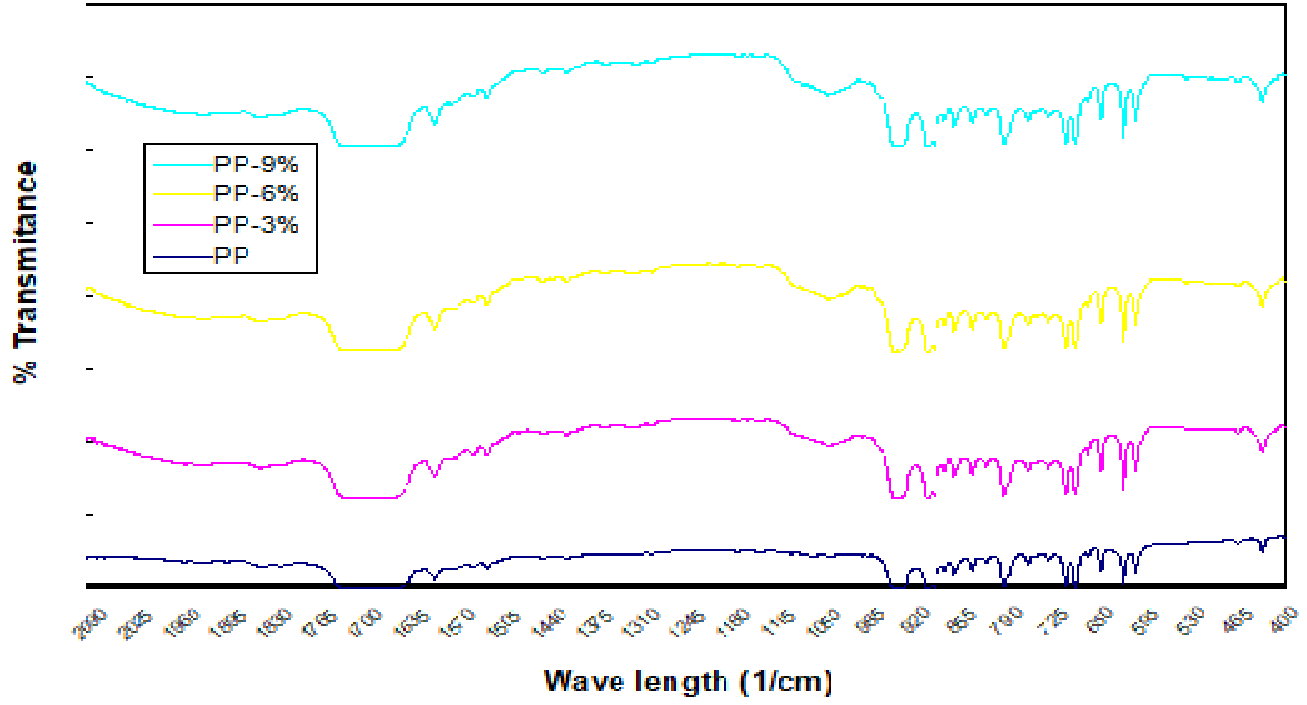

Fig.-1:FTIR Analysis for Polypropylene Nanocomposites Filled Rice Husk

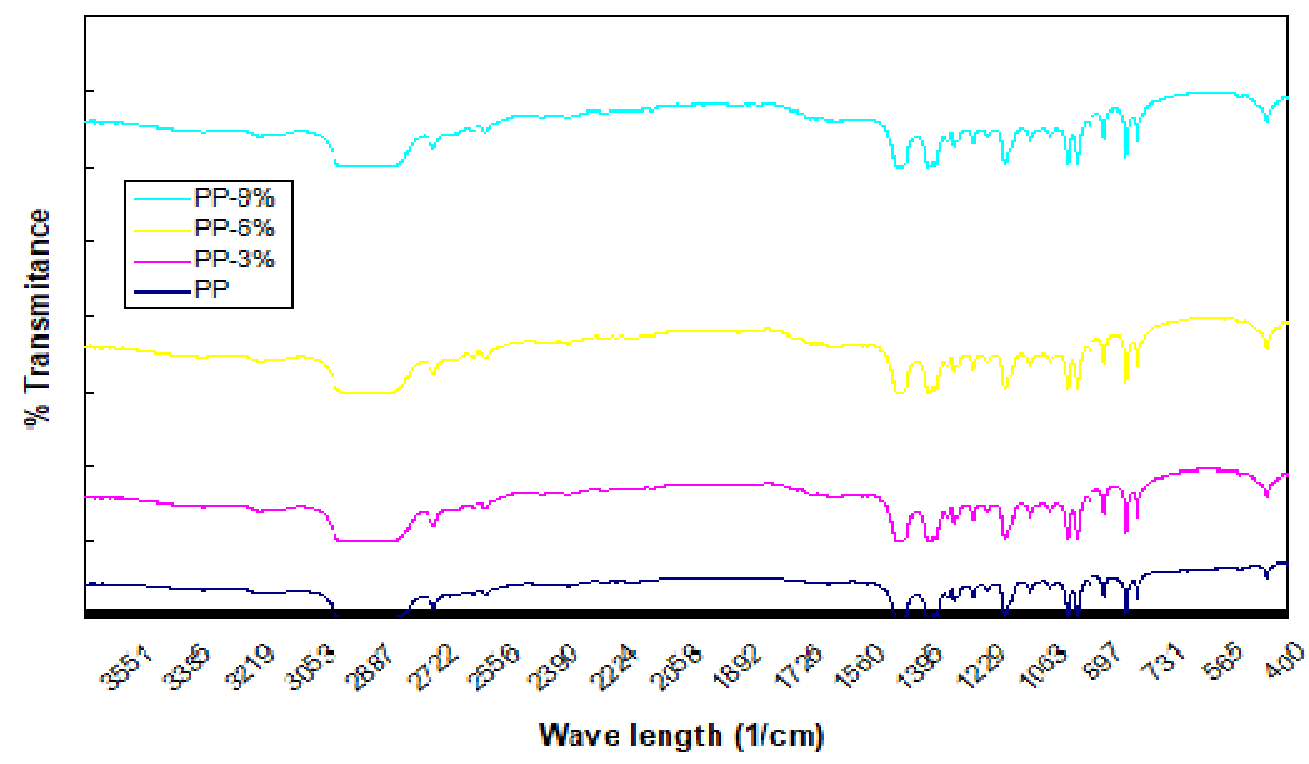

Fig.-2: FTIR Analysis for Polypropylene Nanocomposites Filled Rice Husk Ash
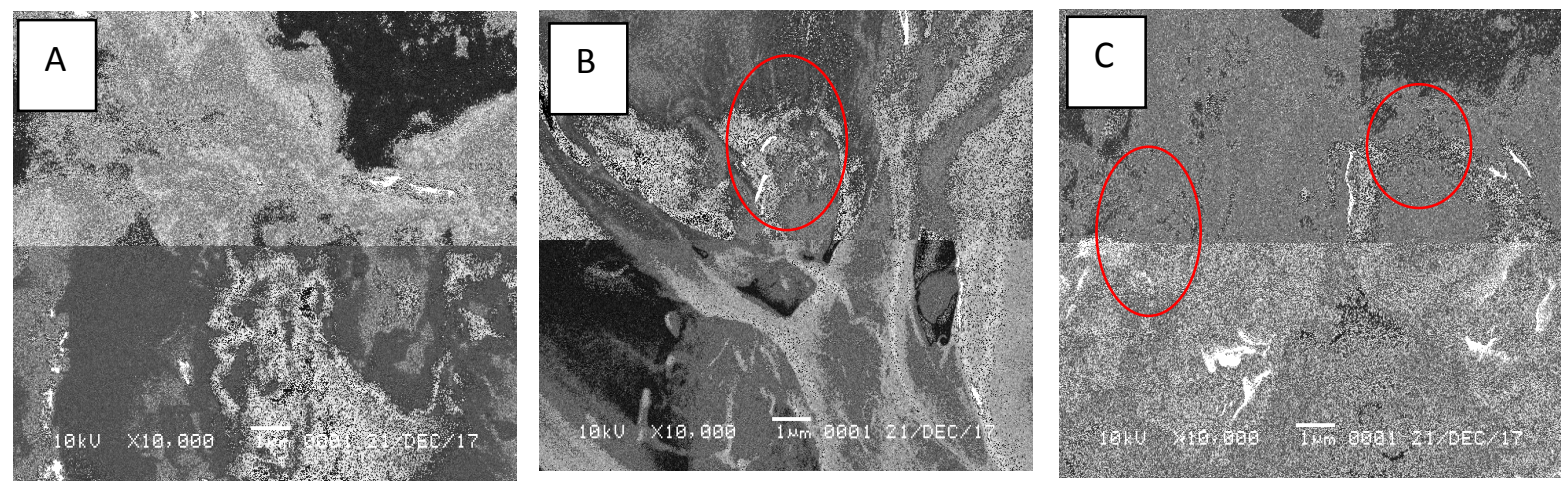

Fig.-3: SEM image for (A) Polypropylene, (B) Polypropylene/Rice Husk, (C) Polypropylene/Rice Husk Ash 
In Fig.-3A shows the SEM micrograph of the fracture surface of polypropylene smooth surface. With the loading of 3\% of rice husk and rice husk ash (Fig.-3B and 3C) the smooth surface sized is reduce. The images in Figure-3B and 3C indicate clear improvement in bonding between rice husk, rice husk ash and polypropylene. The number of holes formed (red circle) which slightly increases where the filler particles are visible. We can observe that the Figure-3B and 3C visualization shows filler rice husk, distribution in the polymer matrix. The adhesion of the filler-polymer matrix increase is improved with increasing filler. ${ }^{16}$

Particulate segregation was found to be good in the fractured region, which might be due to the improvement incompatibility between the waste residue particulates and the polypropylene. The distribution of particles also helped in arresting the crack growth near the failure region of the composites $^{17}$. Despite filler loading, the increase in particle size also influences the uniformity and adhesion conditions at the interface of the filler matrix. ${ }^{16,17}$ The homogeneous contribution between polymer matrix and filler are not cracks and porosity occurs in the composites. ${ }^{28}$

\section{Water Absorption}

Water absorption analysis is an analysis to determine the capacity of water absorption of polymer to the maximum or saturated. Purpose in Water absorption analysis to know the level of strength and stiffness of composites seen from the amount of water absorbed. The water absorption of polypropylene nanocomposites has the effect of filler loading shown in Fig. -4 .

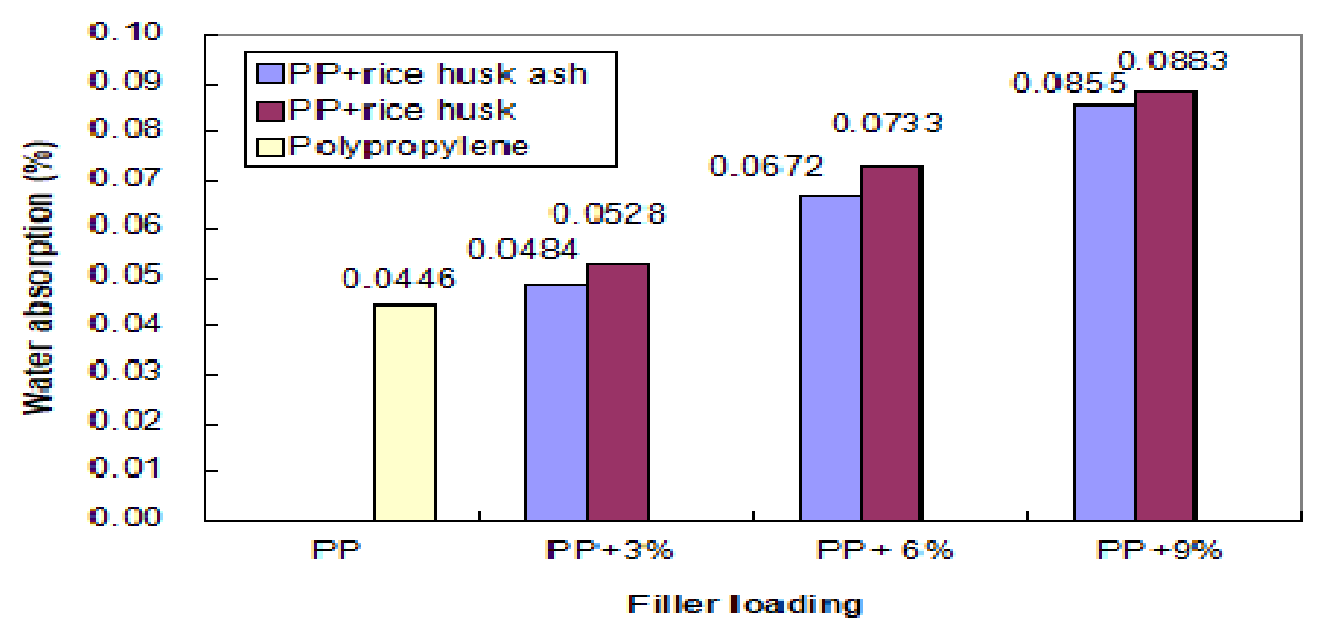

Fig.-4: Water Absorption Effect of Filler Loading

In Fig.-4 It can be seen that the water absorption of composites is increase with the increase of filler loading. The small water absorption shows in polypropylene without filler content that other composite. Ashori and Noerbakhsh, ${ }^{19}$ mentions that polypropylene matrix does not absorb any moisture. Water absorption increase with the increase of filler loading, but in the same filler loading, rice husk ash give small water absorption that rice husk filler into composites. Rice husk has lignocellulose component so that can absorb water. This is because rice husk is a natural material than rice husk ash, The main component in rice husk have hydroxyl groups so that these groups are hydrophilic in nature. ${ }^{20}$ The fewer ofthe hydroxyl group in the rice husk ash cause the composites fewer water absorption. The resulting water absorption is highly dependent on the type, size, and amount of filler/amplifier. ${ }^{11}$ The more number of fillers in the composite, the distance between particles and polymers is tighter so that cohesion occurs. While on the surface of the filler has an adhesion event, the occurrence of cohesion and adhesion causes intermolecular interactions to become stronger and denser so that water is difficult to absorb (hydrophobic). ${ }^{21}$ It is indicate that moisture absorb by the filler. Therefore, the filler of rice husk ash type is better than rice husk to absorb the water in composites. Water permeability of film composites depends on many factors, such as integrity of the film composites, ratio hydrophilic-hydrophobic in nanocomposites, the ratio between amorphous and crystalline zone into composites and the mobility of 
chain into polymer. ${ }^{22}$ According to Du et al, ${ }^{23}$, the water absorption increased in nanocomposites films because of a nano particle plays as a core that surrounded by a water layer with the thickness of several molecules.

\section{Mechanical Properties}

In this study, mechanical properties of polypropylene nanocomposites filled with rice husk and rice husk ash have used by tensile strength and elongation at break. The result was shown in Fig. 6 for tensile strength and Fig.-7 for elongation at break. Polypropylene without filler has $13.92 \mathrm{kgf} / \mathrm{mm}^{2}$ this value lower than polypropylene filled with filler. For the polypropylene nanocomposites filled with rice husk, the tensile strength increase with $3 \mathrm{wt} \%$ rice husk and lower than $6 \mathrm{wt} \%$ rice husk, but increase slightly after loading $9 \mathrm{wt} \%$ rice husk. The value $16.67,15.25$ and $15.92 \mathrm{kgf} / \mathrm{mm}^{2}$ for polypropylene nanocomposites filled with rice husk. But polypropylene nanocomposites filled with rice husk ash, tensile strength increase when increasing the filler loading $3 \mathrm{wt} \%, 6 \mathrm{wt} \%$ and $9 \mathrm{wt} \%$ are respectively. The value is $16.92,17.83$ and $18.58 \mathrm{kgf} / \mathrm{mm}^{2}$ are respectively for polypropylene nanocomposites filled with rice husk ash. Polypropylene nanocomposites filled with rice husk ash has higher tensile strength than polypropylene nanocomposites filled with rice husk. The higher tensile strength of rice husk ash because of the high crystalline structure, which enriched the particulate loading. ${ }^{15,19}$ This is due to the addition of nano-sized filler material to loading $(<10 \%)$ which causes the distance between the particles to be closer so as to increase the strength of polypropylene nanocomposites. ${ }^{12}$ This may occur due to the disordered arrangement of fillers that affects the forces acting on the composite, resulting in poor tensile strength. Yee et al. ${ }^{24}$ employs that the decreasing strength with increasing particle loading contributed to the poor interfacial adhesion between matrix and fillers. The increasing the tensile strength with the addition of filler loading was expected due to the presence of filler loading reinforcement structure that makes the polymer matrix more brittle. ${ }^{22,23}$ Rajkumar et $\mathrm{al}^{27}$ has investigated that the increase in filler loading will increase the tensile strength of composites, this is because of effect and interaction between filler and polymer matrix.

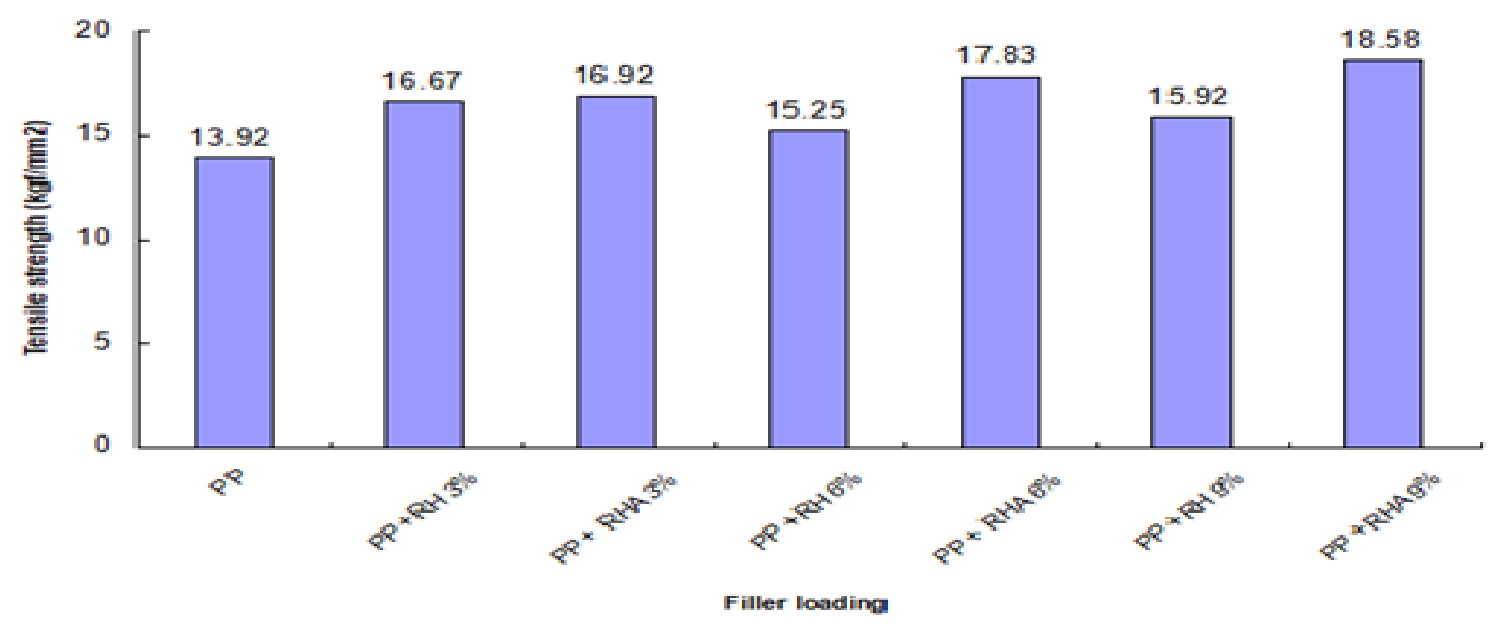

Fig.-5: Tensile Strength of Polypropylene Nanocomposites

Elongation at break of the polypropylene nanocomposites has shown in Fig.-6. The elongation of polypropylene without filler has high value than others. The polypropylene nanocomposites have an elongation at break decrease when increasing the filler loading. For polypropylene nanocomposites filled with rice husk, at $3 \mathrm{wt} \%$ loading give the value $5.6 \%$, at $6 \mathrm{wt} \%$ give value $8.32 \%$ but at loading rice husk $9 \%$, elongation at break decrease at value $1.92 \%$. For polypropylene nanocomposites filled with rice husk ash, elongation at break decrease when increasing filler loading. Elongation at break increase for polypropylene filled with rice husk depends on filled with rice husk ash. Loading filler increase will make the elongation of composites decrease this cause the weight fraction of plastic in polypropylene nanocomposites decreased with increased brittleness. ${ }^{20}$ At increasing the filler loading (rice husk and rice husk ash), bonding between filler and polypropylene matrix decreased, this resulted elongation of 
composites decrease. This is because the insertion of the filler into the pores of the polypropylene nanocomposites that causes the arrangement between the filler becomes tight and the distance between the filler becomes closer. So it can increase the stiffness (decreased elongation). However, the rice husk nanocomposite did not have a regular decrease in elongation, it can be seen in the $3 \%$ rice husk value of elongation is $5.6 \%$. This may occur due to the disordered arrangement of fillers that affect the forces acting on the nanocomposite, resulting in poor elongation.

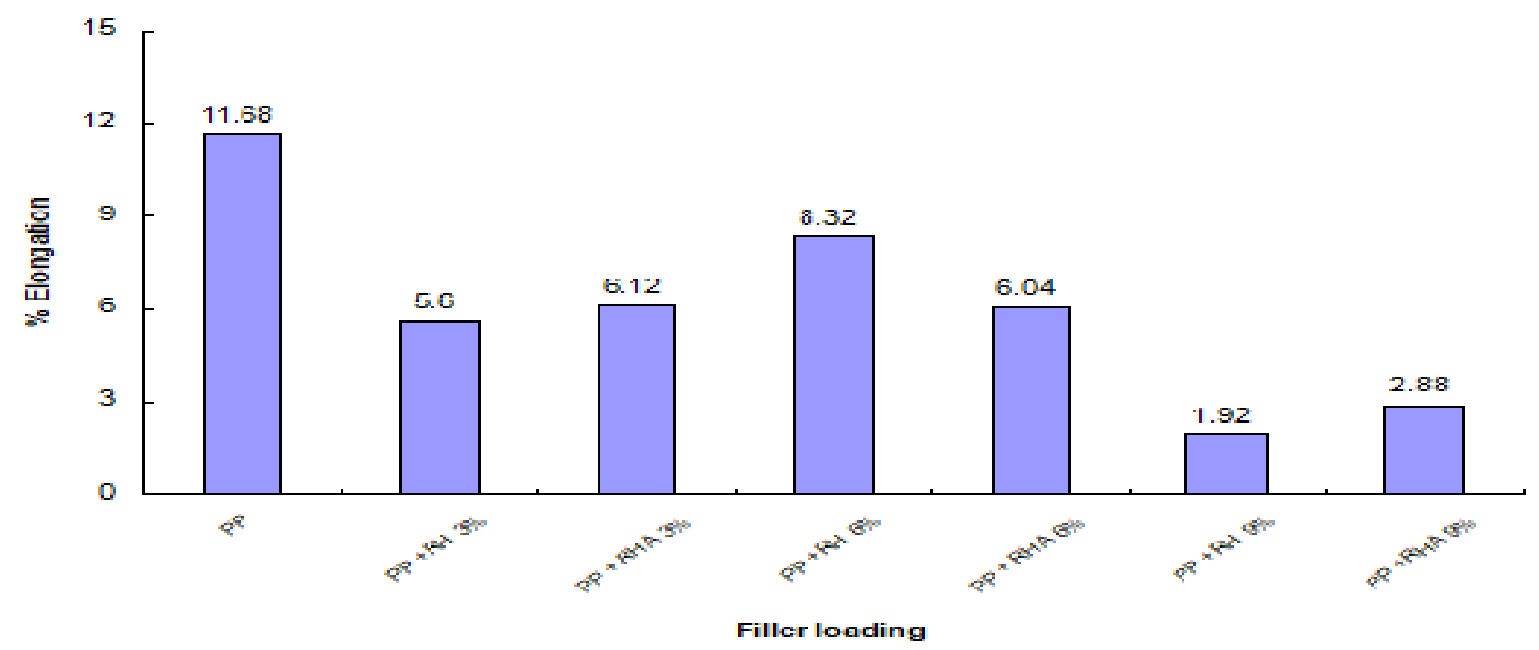

Fig.-6: Elongation at Break of Polypropylene Nanocomposites

\section{CONCLUSION}

Polypropylene nanocomposites filled with rice husk and rice husk ash have successfully carried out. Characteristic of polypropylene nanocomposites from FTIR spectra have the same structure between polypropylene nanocomposites filled with rice husk and rice husk ash. SEM analysis shows that polypropylene nanocomposites filled with rice husk and rice husk ash showed smooth fracture surface, it was shown that improvement incompatibility between the nanoparticles and polypropylene as a matrix. Polypropylene nanocomposites have high water absorption than polypropylene because of filler loading. Mechanical properties of polypropylene nanocomposites increase in tensile strength but decrease for elongation at the break on increasing fillers.

\section{ACKNOWLEDGMENT}

The authors would like to thank and appreciation to the funder and supporters until this research can be carried out. Fund support from the University of Syiah Kuala, Ministry of Research, Technology and Higher Education who have funded Penelitian Calon Profesor (PCP) in accordance with the Research Contract No. 289/UN11/SP/PNBP/2018.

\section{REFERENCES}

1. C. Fapohunda, B. Akinbile, and A. Shittu, International Journal of Sustainable Built Environment6, 675-692 (2017), DOI:10.1016/j.ijsbe.2017.07.004

2. I. J. Fernandes, Characterization of Silica Produced from Rice Husk Ash: Comparison of Purification and Processing Methods. Materials Research, 20, 512(2017), DOI: 10.1590/1980-5373-mr-20161043.

3. J.J. Saceda, F. Leon, R. L. de, K. Rintramee, S. Prayoonpokarach and J. Wittayakun, Química Nova, 34, 1394(2011), DOI:10.1590/S0100-40422011000800018

4. B. Arifin, S. Aprilia, P.N. Alam, F. Mulana, A. Amin, D.M. Anaska, and D. E. Putri, MATEC Web of Conferences, 156, 05020 (2018), DOI:10.1051/matecconf/201815605020.

5. G. Gupta, A. Dhanola, and A. Raturi, Materials Science and Engineering, 149, 012091(2016), DOI: $10.1088 / 1757-899 X / 149 / 1 / 012091$

6. H. A. Abba, I. Z. Nur, and S.M. Salit, Journal of Minerals and Materials Characterization and Engineering, 1, 271(2013), DOI:10.4236/jmmce.2013.15041. 
RASĀYAN J. Chem.

Vol. 12 | No. 2 |994 - 1001| April - June | 2019

7. M. C. N. Yemele, A. Koubaa, A. Cloutier, P. Soulounganga, and M.Wolcott, Composites Part A: Applied Science and Manufacturing, 41, 131(2010), DOI:10.1016/j.compositesa.2009.06.005.

8. A. K. Bledzki, A.A. Mamun, and J. Volk, Composites Part A: Applied Science and Manufacturing, 41, 480(2010), DOI:10.1016/j.compositesa.2009.12.004

9. D. Hirayama, C. Saron, E. C. Botelho, M. L. Costa, and A.C. A. Junior, Materials Research, 20, 519 (2017), DOI:10.1590/1980-5373-mr-2016-1022.

10. N. A. Sri Aprilia, Md.S. Hossain, A. Mustapha, S. S. Suhaily, N.A Nik Norulaini, L. C. Peng, AK Mohd Omar, and H. P. S. Abdul Khalil. Bio Resources, 10, (2015), DOI:10.15376/biores.10.3.53055316

11. N. A. Sri Aprilia, Y. Davoudpour, W. Zulqarnain, H.P.S. Abdul Khalil, C.I. Che Mohamad Hazwan, M. S. Hossain, R. Dungani, H. M. Fizree, A. Zaidon, M. K. Mohamad Haafiz. BioResources, 11, (2016), DOI:10.15376/biores.11.2.3875-3889.

12. P. H. C. Camargo, K. G. Satyanarayana, and F. Wypych, Materials Research, 12, 1(2009), DOI: $10.1590 / \mathrm{S} 1516-14392009000100002$.

13. S. D. Saravanana and M. S. Kumar, Procedia Engineering, 64, 1505(2013), DOI: $10.1016 /$ j.proeng.2013.09.232

14. R. S. Chen, M. N. Salleh, M. H. Ab Ghani, S. Ahmad and S. Gan, Bioresources, 10(4), 6872 (2015), DOI: 10.15376/biores.10.4.6872-6885.

15. J. Coates, Interpretation of Infrared Spectra, A Practical Approach. in Encyclopedia of Analytical Chemistry (ed. Meyers, R. A.) (John Wiley \& Sons, Ltd, 2006), DOI:10.1002/9780470027318.a5606

16. T. Masri, H. Ounis, L. Sedira, A. Kaci, A. and A. Benchabane, Construction and Building Materials, 164, 410(2018), DOI:10.1016/j.conbuildmat.2017.12.197.

17. R. Prithivirajan, S. Jayabal and G. Bharathiraja Cellulose Chemistry and Technology, 49(1), 65 (2015)

18. J. S. Pereira da Silva, J. M. Farias da Silva, B. G. Soares, and L. Livi, Composites Part B: Engineering, 129, 117(2017), DOI:10.1016/j.compositesb.2017.07.088.

19. A. Ashori, and A. Nourbakhsh, Bioresource Technology, 101, 2515(2010), DOI:10.1016/j.biortech.2009.11.022.

20. R. Arjmandi, A. Hassan, K. Majeed, and Z. Zakaria, International Journal of Polymer Science, 1-32 (2015), DOI:10.1155/2015/501471

21. C. S. Navas, M. M. Reboredo, and D. L. Granados, Procedia Materials Science, 8, 778(2015), DOI: $10.1016 /$ j.mspro.2015.04.135.

22. S. S. Laxmeshwar, D. J. Madhu Kumar, S. Viveka, and G.K. Nagaraja, ISRN Polymer Science, 1-8 (2012), DOI: 10.5402/2012/154314.

23. B. X. Du, Z. Y. He, Q. Du, and Y. G. Guo, IEEE Transactions on Dielectrics and Electrical Insulation, 23, 134(2016), DOI:10.1109/TDEI.2015.005203.

24. T. W. Yee, L. J. Choy and W. A. Wan Abdul Rahman. Journal of Composite Materials, 45, 1201 (2011), DOI:10.1177/0021998310380287.

25. A. M. Poulose, A. Y. Elnour, A. Anis, H. Shaikh, S. M. Al-Zahrani, J. George, M. I. Al-Wabel, A. R. Usman, Y.S. Ok, D. C. W. Tsang, and A.K. Sarmah.Science of The Total Environment, 619-620, 311(2018), DOI: 10.1016/j.scitotenv.2017.11.076

26. P. Noorunnisa Khanam, and M. A. AlMaadeed, Materials \& Design, 60, 532(2014), DOI: 10.1016/j.matdes.2014.04.033

27. K.Rajkumar, Prem Ranjan, P.Thavamani, P.Jeyanthi and P.Pazhanisamy, Rasayan J. Chem., 6(2), 122(2013)

28. G. Diju Samuel , J. Edwin Raja Dhas , G. Ramanan and M. Ramachandran, Rasayan J. Chem., 10(3), 784(2017), DOI:10.7324/RJC.2017.1031748

29. P.R. Rajakumar and R. Nanthin, Rasaya J. Chem., 4(3), 567(2011).

[RJC-5144/2018] 